\title{
Using Instability of a Non-stoichiometric Mixed Oxide Oxygen Evolution Catalyst As a Tool to Improve Its Electrocatalytic Performance
}

\author{
Olga Kasian $^{1}$ (D) - Simon Geiger ${ }^{1}$ - Maximilian Schalenbach ${ }^{1} \cdot$ Andrea M. Mingers ${ }^{1}$. \\ Alan Savan $^{2}$ • Alfred Ludwig ${ }^{2}$ - Serhiy Cherevko ${ }^{1,3}$ • Karl J. J. Mayrhofer ${ }^{1,3,4}$
}

Published online: 28 June 2017

(C) The Author(s) 2017. This article is an open access publication

\begin{abstract}
Owing to their superior electrocatalytic performance, non-stoichiometric mixed oxides are often considered as promising electrocatalysts for the acidic oxygen evolution reaction (OER). Their activity and stability can be superior to those of the state-of-the-art $\mathrm{IrO}_{2}$ catalysts, although the exact nature of this phenomenon is not yet understood. In the current work, a $\mathrm{Ir}_{0.7} \mathrm{Sn}_{0.3} \mathrm{O}_{2-\mathrm{x}}$ thin-film electrode is taken as a representative example for a thorough evaluation of OER activity of the non-stoichiometric oxides. Complementary activity and stability analysis of $\operatorname{Ir}_{0.7} \mathrm{Sn}_{0.3} \mathrm{O}_{2-\mathrm{x}}$ electrodes is achieved using a setup based on an electrochemical scanning flow cell and ICP-MS. The obtained ICP-MS data presents an unambiguous proof of the preferential dissolution of the less noble $\mathrm{Sn}$ from the mixed oxide during OER. While less than a monolayer of Ir is dissolved after a prolonged electrolysis of 1400 min during which its dissolution rate drops to near zero, the amount of Sn lost is ten monolayers. The latter finding is confirmed by XPS analysis, which besides showing Ir surface enrichment also indicates a gradual transformation of $\operatorname{Ir}^{0}$ to $\mathrm{Ir}^{\mathrm{III}}$ species. This transition is beneficial for electrode activity,
\end{abstract}

Olga Kasian

o.kasian@mpie.de

1 Max-Planck-Institut für Eisenforschung GmbH, Max-Planck-Straße 1, 40237 Düsseldorf, Germany

2 Institute for Materials, Ruhr-Universität Bochum, 44801 Bochum, Germany

3 Helmholtz-Institute Erlangen-Nürnberg for Renewable Energy (IEK-11), Forschungszentrum Jülich, Egerlandstr. 3, 91058 Erlangen, Germany

4 Department of Chemical and Biological Engineering, Friedrich-Alexander-Universität Erlangen-Nürnberg, Egerlandstr. 3, 91058 Erlangen, Germany as the overpotential for OER at $j=5 \mathrm{~mA} \mathrm{~cm}^{-2}$ was decreasing up to $300 \mathrm{mV}$. The increase in electrode activity is attributed to several mechanisms including generation of $\operatorname{~IIII~}^{\mathrm{III}}$ active sites and overall surface area increase. A generalized description of OER catalysis by Ir-based materials is given, including data from the current work as well as from other Ir-based mixed oxides, such as Ir-Ru-O and Ir-Ni-O.

Keywords Oxygen evolution reaction · Water splitting · Electrocatalysis $\cdot$ Iridium tin oxide $\cdot$ Non-stoichiometric mixed oxide $\cdot$ Dissolution

\section{Introduction}

The oxygen evolution reaction (OER) is a counter reaction in numerous industrially important processes, such as electrochemical hydrogen production, cathodic electrosynthesis, and metal electrowinning [1]. Even though in some of these applications the use of non-noble metal-based electrodes such as $\mathrm{PbO}_{2}$ can be justified [2, 3], all of them would benefit from the development of a more active alternative. Electrode stability, however, should not be sacrificed. Considering acidic environments as the most promising ones, nowadays only Irbased anodes meet these strict requirements [4-7]. Scarcity and the high price of Ir, however, are serious hindrances in the way of its universal application. Hence, optimization of the catalyst utilization becomes of very high importance. There are several options given in the literature for how this can be achieved. Among them, the increase in surface area of Ir-based catalysts by using nanoparticles [8] or porous structures $[9,10]$ is the most used approach for improving the gravimetric electrocatalytic activity. Another possibility is dilution of Ir by alloying with other metals. The representative examples here are the systems in which Ir is alloyed with 
electrochemically less stable metals, e.g., Ir-Ru [11-14] and IrNi mixed oxide [10] or Ir-based perovskites [15, 16], which sometimes show higher activity than Ir oxide. As a rule, however, improved electrocatalytic activity of these compounds is counterbalanced by their lower stability towards dissolution. In these systems, dissolution of the less stable component usually occurs together with an increased dissolution of Ir, resulting in the overall catalyst instability $[10,14]$. On the other hand, mixing of Ir oxide with significantly less active but more stable materials, e.g., Ti [17] or Sn [18] typically results in catalysts showing very high stability against dissolution. In this case, however, deterioration of electrocatalytic performance with time is to be expected, taking into account the semiconducting nature of stoichiometric $\mathrm{TiO}_{2}$ and $\mathrm{SnO}_{2}$ [19-21].

In achieving a compromise between activity and stability, non-stoichiometric oxides of Ir and more stable elements can be considered as very promising catalyst materials [22]. In such compounds, oxygen vacancies can serve as the active sites for the OER [23]. At the same time, owing to their high thermodynamic stability, longevity of Ir-Sn and Ir-Ti-based nonstoichiometric oxides during the OER can be still sufficiently high for their successful commercialization. Before, that is accepted as a viable approach, however, a thorough analysis concerning their activity and stability is required. While the former is easy to be addressed by common electrochemical methods, the latter requires a more comprehensive investigation since the literature lacks in insight into the stability and degradation mechanisms of Ir-based non-stoichiometric mixed oxides.

In the current work, non-stoichiometric $\mathrm{Ir}_{0.7} \mathrm{Sn}_{0.3} \mathrm{O}_{2-\mathrm{x}}$ is chosen as a representative example in order to evaluate the applicability of this class of materials for catalyzing acidic OER. The oxide is prepared using reactive sputtering as a technique allowing one to precisely control elemental composition and degree of stoichiometry. Activity and stability are investigated in parallel by a scanning flow cell (SFC) connected to an inductively coupled plasma mass spectrometer (ICP-MS). This allows the precise separation and identification of partial dissolution rates of Ir and $\mathrm{Sn}$ and their correlation with electrochemical surface processes. Changes in the electrode composition and electronic properties triggered by dissolution are analyzed and their effect on electrode performance is studied and discussed.

\section{Experimental}

Thin $\mathrm{Ir}_{0.7} \mathrm{Sn}_{0.3} \mathrm{O}_{2-\mathrm{x}}$ films were deposited by confocal reactive co-sputtering (Creavac, Dresden, Germany). To prepare films with a minimal surface roughness, smooth substrates of single crystalline $\mathrm{Si}(100)$ wafers with a $1.5-\mu \mathrm{m}$ thermal $\mathrm{SiO}_{2}$ diffusion and reaction barrier layer were used. The base vacuum before deposition was $2.5 \times 10^{-6} \mathrm{~Pa}$. The Ø2 inch target of $\mathrm{Sn}$ (99.95\%, EvoChem, Germany) and Ø4 inch target of Ir (99.9\%, Evochem, Germany) were pre-cleaned by sputtering against closed shutters prior to deposition. A mixture of $\mathrm{O}_{2}$ and Ar was used as the sputter gas and the chamber pressure was regulated to $0.66 \mathrm{~Pa}$ at room temperature. Ir and Sn were deposited simultaneously at $85 \mathrm{~W}$ DC and at $30 \mathrm{~W}$ DC, respectively. The resulting thickness of the obtained coating was approximately $200 \mathrm{~nm}$. The composition of the film was confirmed using energy-dispersive X-ray analysis (EDX, INCA $\mathrm{X}$-act, Oxford Instruments, UK) and X-ray photoelectron spectroscopy (XPS) and can be described as $\operatorname{Ir}_{0.7} \mathrm{Sn}_{0.3} \mathrm{O}_{2-\mathrm{x}}$ (where $0<\mathrm{x}<2$ ).

XPS measurements were carried out (Quantera II, Physical Electronics, Chanhassen, MN, USA) applying a monochromatic $\mathrm{Al} \mathrm{K} \alpha \mathrm{X}$-ray source $(1486.6 \mathrm{eV})$ and operating at $15 \mathrm{kV}$ and $25 \mathrm{~W}$. The binding energy scale was referenced to the $\mathrm{C} 1 \mathrm{~s}$ signal at $285.0 \mathrm{eV}$. The Casa XPS software was used to analyze the experimentally obtained spectra. The fitting of spectra was performed after subtraction of a Shirley background. In all fits, the peak separation and the peak area ratios between the $\mathrm{Ir} 4 \mathrm{f} 7 /$ 2 and the Ir $4 f 5 / 2$ components were constrained to be $3 \mathrm{eV}$ and $4: 3$, respectively. A Doniach-Šunjic profile with an asymmetry parameter of 0.1 and a spectrum convolution width of 100 was used for the peak fittings. Detailed discussion of Ir XP spectra interpretation can be found in the literature [24-26].

The prepared $\operatorname{Ir}_{0.7} \mathrm{Sn}_{0.3} \mathrm{O}_{2-\mathrm{x}}$ thin film served as the working electrode in the scanning flow cell-inductively coupled plasma mass spectrometer (ICP-MS, NexION 300X, Perkin Elmer)-based setup SFC-ICP-MS, as described in [5, 27]. All presented data are normalized to the geometric area of the working electrode $\left(1 \times 10^{-2} \mathrm{~cm}^{2}\right)$ assuming low roughness of the sputtered films. A graphite rod, placed in the inlet channel of the SFC, was utilized as the counter electrode. A saturated Ag/ $\mathrm{AgCl}$ electrode (Metrohm, Germany) was used as the reference electrode. All reported potentials are referenced to the reversible hydrogen electrode (RHE) potential that was measured in each day of experiments using a polycrystalline platinum foil (99.99\%, MaTeck, Germany) in hydrogen saturated $0.1 \mathrm{M}$ $\mathrm{HClO}_{4}$. This solution was prepared by dilution of concentrated acid (Suprapur® 70\% $\mathrm{HClO}_{4}$, Merck, Germany) in ultrapure water (PureLab Plus system, Elga, $18 \mathrm{M} \Omega \mathrm{cm}$, TOC $<3 \mathrm{ppb}$ ) and, after saturation with Ar, was also used in all electrochemical measurements. A potentiostat (Gamry Reference 600, USA) was used for the electrochemical measurements.

Prior to introduction into the ICP-MS, the electrolyte was mixed with an internal standard in a Y-connector (mixing ratio 1:1) after the electrochemical cell. As internal standards for detection of ${ }^{118} \mathrm{Sn}$ and ${ }^{193} \mathrm{Ir}$ isotopes, $10 \mu \mathrm{g} \mathrm{L} \mathrm{L}^{-1}$ of ${ }^{103} \mathrm{Rh}$ and ${ }^{187}$ Re was used, respectively. The ICP-MS was calibrated every day of experiment prior to the electrochemical measurements.

Long-term stability measurements were performed using an h-cell with anodic and cathodic compartments divided by a fine glass frit (Pine Research Instrumentation, USA). The volume of electrolyte in the anodic and cathodic compartments was adjusted to $20 \mathrm{~mL}$ and kept constant during the 
measurements. A Pt foil in the cathodic compartment and saturated $\mathrm{Ag} / \mathrm{AgCl}$ in the anodic compartment were used as counter and reference electrodes, respectively.

In the stability - OER activity studies the following experimental protocol was used. The working electrode was polarized at $E=1.20 \mathrm{~V}_{\mathrm{RHE}}$ during $2 \mathrm{~min}$ for initial stabilization. Afterwards, the potential of the electrode was swept from $E=1.20 \mathrm{~V}_{\mathrm{RHE}}$ to a value corresponding to a current density $j=5 \mathrm{~mA} \mathrm{~cm}^{-2}$ with a scan rate of $10 \mathrm{mV} \mathrm{s}^{-1}$. Then, the electrode was polarized at $1 \mathrm{~mA} / \mathrm{cm}^{2}$ for 10,30 , or $60 \mathrm{~min}$. After that, an identical potential sweep was performed again in order to understand the change in the electrochemical behavior of the electrode material after anodic polarization. All measurements were reproduced at least three times.

\section{Results}

\section{X-ray Photoelectron Spectroscopy}

XPS has been effectively applied as both an ex-situ and in-situ surface-sensitive technique in numerous studies of pristine or mixed Ir-based oxides for OER [12, 14, 25, 28, 29]. It provides information about the chemical state and ratio between elements in as-prepared materials and even more importantly on the change in the composition during anodic polarization. In this context, XPS was used in the current study. The XP spectra of Ir 4f, Sn 3d, and O 1s levels before (top curves) and after (bottom curves) anodic polarization are represented in Fig. 1a-c, respectively. According to the obtained results, the as-prepared sample contains 70 at $\%$ of Ir and this value increases to almost 85 at $\%$ after the anodic polarization. Independent on the electrochemical pretreatment, the $\mathrm{Sn} 3 \mathrm{~d}$ peak is centered at ca. $486.9 \mathrm{eV}$, mainly corresponding to the oxidation state $\mathrm{Sn}^{\text {IV }}[30,31]$. However, taking into account the similar binding energies for $\mathrm{SnO}$ and $\mathrm{SnO}_{2}$, the presence of $\mathrm{SnO}$ on the surface of the as-prepared electrode cannot be excluded [30]. Detailed analysis of the Ir $4 \mathrm{f}$ spectra in the asprepared material (Fig. 1a, top line) allows resolving and quantifying two components corresponding to $\mathrm{IrO}_{2}$ $(61.6 \mathrm{eV})[14,25]$ and metallic $\operatorname{Ir}(60.6 \mathrm{eV})$ [32] in the atomic ratios of ca. 60 to $40 \%$, respectively. There is a drastic change in the spectrum of the Ir $4 \mathrm{f}$ level after the electrode is treated anodically during the OER. Instead of the metallic phase, $\mathrm{Ir}^{\mathrm{III}}$ species appear at $62.2 \mathrm{eV}[9,26]$ in an amount of ca. 30 at\% (Fig. 1a, bottom line). Apparently, anodic polarization leads to complete transformation of metallic Ir into $\mathrm{Ir}^{\mathrm{III}}$ and $\mathrm{Ir}^{\mathrm{IV}}$.

The O 1s spectra for the as-prepared and electrochemically pretreated electrodes are presented in Fig. 1c (top and bottom curves, respectively). Three well-resolved components corresponding to $\mathrm{O}$ in the oxide lattice $(530.5 \mathrm{eV}), \mathrm{O}$ from $\mathrm{OH}$ groups $(531.6 \mathrm{eV})$, and water $(532.5 \mathrm{eV})$ can be identified in the spectra. Electrochemical treatment does not affect the positions of the corresponding peaks. According to these results, in the as-prepared sample, lattice oxygen dominates in the $\mathrm{O}$ 1s spectrum, while after anodic polarization, an increase in the contribution of $\mathrm{OH} / \mathrm{O}$ and $\mathrm{H}_{2} \mathrm{O} / \mathrm{O}$ is found. A similar effect was observed in the case of $\mathrm{IrO}_{2}-\mathrm{RuO}_{2}$ mixed oxides [14].

\section{Oxygen Evolution and Electrochemical Dissolution of $\mathrm{Ir}_{0.7} \mathrm{Sn}_{0.3} \mathrm{O}_{2-\mathrm{x}}$ Electrode}

For the electrochemical characterization, the potential of an asprepared $\mathrm{Ir}_{0.7} \mathrm{Sn}_{0.3} \mathrm{O}_{2-\mathrm{x}}$ electrode was swept into the anodic direction with the scan rate of $10 \mathrm{mV} \mathrm{s}^{-1}$ from $1.2 \mathrm{~V}_{\mathrm{RHE}}$ until the potential reached the value corresponding to a current density of $5 \mathrm{~mA} \mathrm{~cm}{ }^{-2}$. This was followed by anodic polarization at $1 \mathrm{~mA} \mathrm{~cm}{ }^{-2}$ for 10,30 , or $60 \mathrm{~min}$. Afterwards, an identical potential scan was carried out in order to investigate if the anodic treatment had an effect on electrode activity and stability. The quasi-steady-state anodic polarization curves are presented in Fig. 2a. With an increase in the anodic polarization time, the

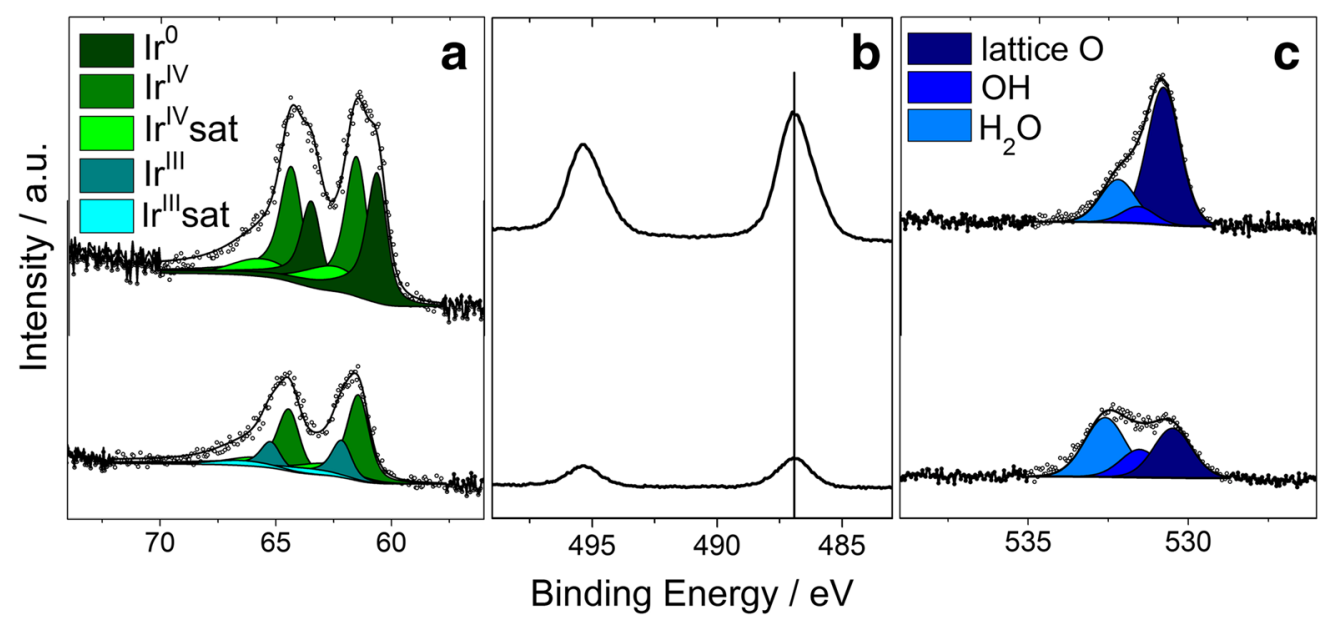

Fig. 1 XP spectra of $\operatorname{Ir} 4 \mathrm{f}(\mathbf{a})$, Sn $3 \mathrm{~d}(\mathbf{b})$, and $\mathrm{O} 1 \mathrm{~s}$ (c) levels for the as-prepared $\mathrm{Ir}_{0.7} \mathrm{Sn}_{0.3} \mathrm{O}_{2-\mathrm{x}}$ electrode (top curves) and after its anodic polarization over $1 \mathrm{~h}$ in $0.1 \mathrm{M} \mathrm{HClO}_{4}$ at $1 \mathrm{~mA} \mathrm{~cm}^{-2}$ (bottom curves) 

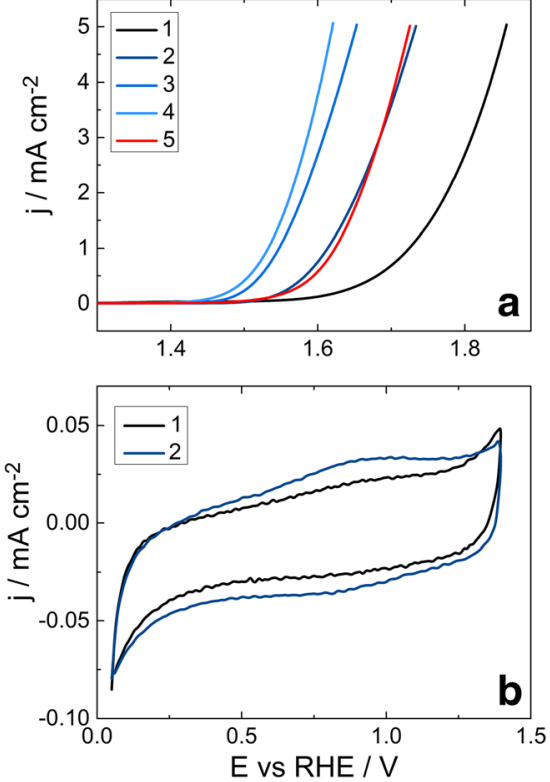

Fig. 2 Electrochemical characterization of as-prepared $\operatorname{Ir}_{0.7} \mathrm{Sn}_{0.3} \mathrm{O}_{2-\mathrm{x}}$ electrode (1) and after 30 (2), 60 (3), or $1400 \mathrm{~min}$ (4) of anodic polarization in $0.1 \mathrm{M} \mathrm{HClO}_{4}$ at $1 \mathrm{~mA} \mathrm{~cm}{ }^{-2}$. (a) The quasi-steady-state anodic polarization curves measured during potential scan from $1.2 \mathrm{~V}_{\mathrm{RHE}}$ until the potential corresponding to the current density of $5 \mathrm{~mA} \mathrm{~cm}^{-2}$ is reached. The scan rate was $10 \mathrm{mV} \mathrm{s}^{-1}$. For comparison, data for stoichiometric $\mathrm{IrO}_{2}$ is added from ref. [14] (5). (b) Cyclic voltammograms of as-prepared and 60-min-polarized $\mathrm{Ir}_{0.7} \mathrm{Sn}_{0.3} \mathrm{O}_{2-\mathrm{x}}$ electrodes, taken in the range of 0.05-1.4 $\mathrm{V}_{\mathrm{RHE}}$ with a scan rate of $50 \mathrm{mV} \mathrm{s}^{-1}$. All presented measurements were performed in the SFCICP-MS setup

overpotential of the OER tends to decrease. Already after $30 \mathrm{~min}$, it reaches a value close to that of stoichiometric $\mathrm{IrO}_{2}$. Moreover, the electrode treated for $60 \mathrm{~min}$ has ca. $100 \mathrm{mV}$ lower overpotential at $j=5 \mathrm{~mA} \mathrm{~cm}^{-2}$ (comparing curves 3 and 5 in Fig. 2a). Further increase in anodization times results in only a slight increase in activity. In order to understand the origin of the increased activity of the anodically treated electrodes, cyclic voltammograms (CVs) before and after anodic polarization were recorded (see Fig. 2b for as-prepared and 60-minpolarized $\mathrm{Ir}_{0.7} \mathrm{Sn}_{0.3} \mathrm{O}_{2-\mathrm{x}}$ electrodes). Comparing the two, one can see that the anodic treatment results in the appearance of two broad waves in the anodic and cathodic branches of the CV at ca. 0.95 and $0.65 \mathrm{~V}_{\mathrm{RHE}}$, respectively. These features can be assigned to the $\operatorname{Ir}(\mathrm{IV}) / \mathrm{Ir}(\mathrm{III})$ transitions that are typically observed in the CVs of hydrous or amorphous iridium oxides [5, 33]. The double-layer charging current is also increased, which may indicate a slight increase in the electrode's surface area.

In parallel with the above-described electrochemical procedure, dissolution profiles of Ir and Sn were taken (Fig. 3). During both potential sweep and steady-state polarization regimes, the rate of Sn dissolution significantly exceeds the rate of Ir dissolution. A similar trend in dissolution was also observed in the case of Ir-Ru and Ir-Ni mixed oxides [10, 14, 34]. The onset of Ir dissolution is ca. $1.56 \mathrm{~V}_{\mathrm{RHE}}$, while Sn already starts dissolving at the open circuit potential. One can see from Fig. $3 \mathrm{c}$ that dissolution of both elements decreases after anodic polarization.

The total amounts of Ir and Sn dissolved during 10, 30, and $60 \mathrm{~min}$ of the OER in galvanostatic conditions in the SFC were obtained by integrating the corresponding dissolution profiles and the data is shown in Fig. 4 (opened symbols). Both curves show similar decreases in the rate of dissolution with time. The highest dissolution rate was observed in the first minutes. Thus, during the first $10 \mathrm{~min}$ of oxygen evolution, the amount of dissolved Ir was about $5 \mathrm{ng} \mathrm{cm}^{-2}$. For comparison, at exactly the same conditions of anodic polarization, ca. $2 \mathrm{ng} \mathrm{cm}$ of Ir dissolves from the $\mathrm{IrO}_{2}$ anode [14], indicating a relatively lower stability of the mixed oxide. In addition, the amount of lost Sn was $32 \mathrm{ng} \mathrm{cm}^{-2}$. Comparison of Fig. 3c, d shows decrease in

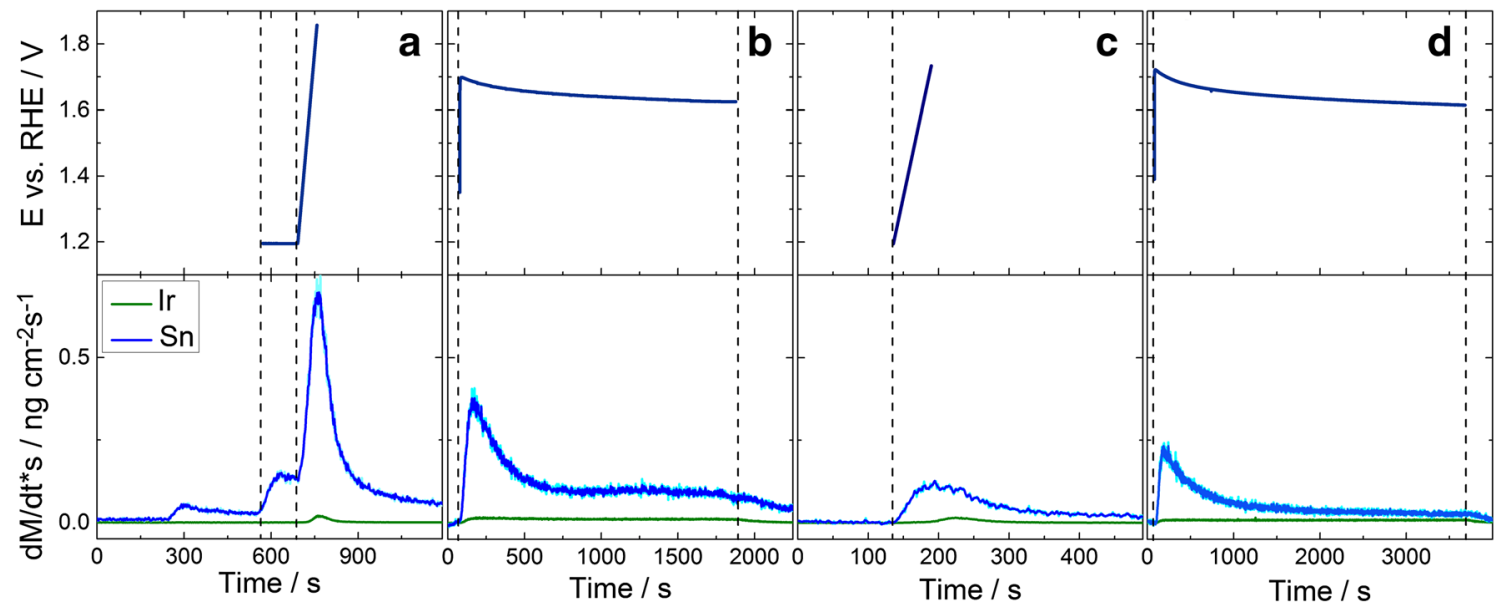

Fig. 3 The applied $(\mathbf{a}, \mathbf{c})$ and measured $(\mathbf{b}, \mathbf{d})$ potential (upper pane) and corresponding dissolution rates (lower pane) plotted vs. time for an $\mathrm{Ir}_{0.7} \mathrm{Sn}_{0.3} \mathrm{O}_{2}$ electrode. The potential was scanned $(\mathbf{a}, \mathbf{c})$ from $1.2 \mathrm{~V}_{\mathrm{RHE}}$ to the potential corresponding to a current density of $5 \mathrm{~mA} \mathrm{~cm}^{-2}$ with a

scan rate of $10 \mathrm{mV} \mathrm{s}^{-1}$, then measured (b) during 30 or $60 \mathrm{~min}$ (d) of anodic polarization at $1 \mathrm{~mA} \mathrm{~cm}{ }^{-2}$. In (c), the material was re-scanned identically to (a) after the anodic polarization 


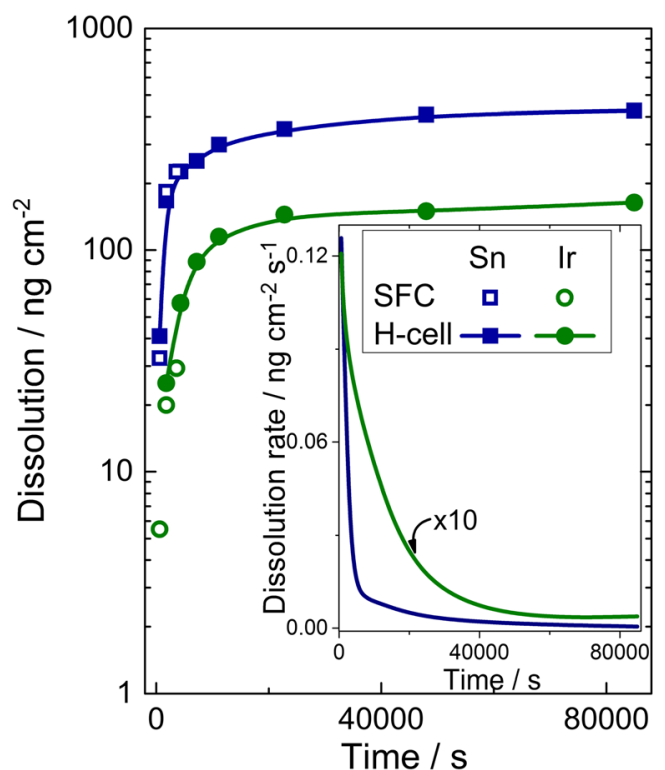

Fig. 4 Dependence of amount of dissolved Ir and Sn during anodic polarization at $1 \mathrm{~mA} \mathrm{~cm}{ }^{-2}$ in $0.1 \mathrm{M} \mathrm{HClO}_{4}$ using SFC (opened symbols) or h-cell with divided anodic and cathodic compartments (closed symbols) on electrolysis time. The inset shows the corresponding variation of dissolution rate with time of electrolysis

dissolution rates from 0.012 to $0.008 \mathrm{ng} \mathrm{cm}^{-2} \mathrm{~s}^{-1}$ and from 0.1 to $0.04 \mathrm{ng} \mathrm{cm}^{-2} \mathrm{~s}^{-1}$ of Ir and Sn, respectively.

Typical operational times of SFC-ICP-MS are limited to few hours. In order to examine the longer-term stability of the anode, galvanostatic measurements were performed in the h-cell with divided anodic and cathodic compartments. To do so, aliquots of $1 \mathrm{~mL}$ were taken periodically from both compartments and further analyzed using the ICP-MS. The amount of Ir in both compartments was below the detection limit after the first $30 \mathrm{~min}$ of measurements owing to the high volume of the cell. Moreover, no Ir was detected in the cathodic compartment during the entire experiment, while the amount of Sn in the cathodic compartment never exceeded $5 \%$ of the concentration of $\mathrm{Sn}$ in the anodic compartment. Both concentrations were considered to estimate dissolution. The measurements were stopped when the change in the concentration for both elements was lower than $9 \%$ in $10 \mathrm{~h}$, which is an indication that quasi-steady-state is achieved. The steady-state dissolution rates of Ir and Sn approached the values of 0.0001 and $0.0005 \mathrm{ng} \mathrm{cm}^{-2} \mathrm{~s}^{-1}$, respectively. The results obtained in the h-cell are shown in Fig. 4 by solid symbols. One can see that there is a good agreement between the data obtained in two setups. Hence, owing to its high sensitivity, SFC-ICP-MS can be considered as a powerful tool for determining the initial dissolution rates, which is extremely important in noble metal dissolution kinetics studies. These values can be useful for estimation of dissolution in the flow reactors, where equilibrium is not necessarily to be achieved. On the other hand, h-cell measurements are complementary providing valuable information on equilibrium concentration of the dissolved elements.

\section{Discussion}

It is anticipated that oxygen deficiency in an oxide material can be desirable in terms of catalytic activity [35]. In particular, catalytically active sites for the OER are often associated with oxygen vacancies [23]. The impact of oxygen vacancies on the OER can be ascribed to the dependence of both chemical potential and surface potential on the degree of ionicity and non-stoichiometry [36]. Lattice defects in the bulk as a rule modify the chemical potentials of the compound, while surface defects affect the local charge distribution and, as a result, surface potential. Availability of such defects and their high concentration in a catalyst can additionally facilitate the reaction at lower temperatures owing to a decrease in the activation energy of the adsorption step [36]. However, owing to poor electrocatalytic properties of the Sn-containing electrode surface and semiconducting nature of tin oxides, the initially prepared $\mathrm{Ir}_{0.7} \mathrm{Sn}_{0.3} \mathrm{O}_{2-\mathrm{x}}$ anode has a relatively high OER overpotential. During the OER, electrocatalytic activity of the $\mathrm{Ir}_{0.7} \mathrm{Sn}_{0.3} \mathrm{O}_{2-\mathrm{x}}$ anode tends to increase with time (Fig. 2a). A similar trend was reported recently by Reier et al. for the IrNi system [10,34]. This behavior can be understood by taking a closer look at the XPS data. It reveals that after anodic polarization, the Ir to Sn ratio increases. Moreover, the analysis of the $\mathrm{Sn} 3 \mathrm{~d}$ spectra from the as-prepared and treated electrodes presented in Fig. 1b shows further that the electrode near the surface layer consists of oxide (either $\mathrm{Sn}^{\mathrm{II}}$ or $\mathrm{Sn}^{\mathrm{IV}}$ or a mixture of both) but not metallic Sn. Since dissolution of $\mathrm{SnO}_{2}$ should not be observed at these conditions [37], a conclusion can be made that thermodynamic instability of $\mathrm{SnO}$ is responsible for the relatively high initial dissolution of $\mathrm{Sn}$ (Fig. 3). Unlike Sn, some amount of metallic Ir is present in the as-prepared film. With anodic polarization, however, conversion of metallic Ir to $\operatorname{Ir}^{\mathrm{III}}$ and $\mathrm{Ir}^{\mathrm{IV}}$ species takes place. Owing to their lower coordination number, $\mathrm{Ir}^{\mathrm{III}}$ species can themselves be responsible for the observed electrocatalytic activity improvement $[9,10,26,28,38]$. It is expected that adsorption of oxygen containing radicals on Ir $^{\mathrm{III}}$ will be stronger than on $\operatorname{Ir}^{\mathrm{IV}}$, and, therefore, favorable. The increase in $\mathrm{OH}$ groups and $\mathrm{H}_{2} \mathrm{O}$ contribution in the overall $\mathrm{O}$ 1s spectra presented in Fig. 1c suggests formation of a porous structure and a change in hydrophilicity of the oxide. Hence, it may be concluded that a process similar to dealloying takes place at the electrode during the OER. As was discussed by Debe, the latter is typically responsible for the resulting increased surface area of the electrocatalyst [39]. Indeed, according to Fig. 2b, the surface area of the $\mathrm{Ir}_{0.7} \mathrm{Sn}_{0.3} \mathrm{O}_{2-\mathrm{x}}$ electrode is increasing in time owing to intensive removal of one of the components. Thus, there are at least two or three mechanisms contributing to the activity enhancement: (a) formation of Ir $^{\mathrm{III}}$ active sites and (b) surface area increase and (c) removal of the less active component. The contribution of each of them is, however, difficult to differentiate. It is anticipated that the change in 
the electronic structure also influences electronic conductivity. Interestingly, no increase in catalytic activity was reported for Sn-noble metal-based mixed oxides, prepared by thermal decomposition of respective salts in air [21]. As a rule, stoichiometric $\mathrm{SnO}_{2}$ is formed in this case, which is related to a relatively high affinity of $\mathrm{Sn}$ for oxygen.

High electrocatalytic activity is important but not the only parameter to be expected from a good OER electrocatalyst. Even the most active material has no future application if it cannot guaranty a stable long-term electrolyser performance. Hence, dissolution results should also be discussed. In line with the Ir and Sn XP spectra change, SFC-ICP-MS data shows much higher dissolution rates of $\mathrm{Sn}$ in comparison to $\operatorname{Ir}$ (Fig. 3). Already during the first potential ramp in the anodic direction, dissolution of Ir from the $\mathrm{Ir}_{0.7} \mathrm{Sn}_{0.3} \mathrm{O}_{2-\mathrm{x}}$ anode was higher than that for $\mathrm{IrO}_{2}$. Several explanations can be given for this phenomenon. As shown in Fig.1, $\mathrm{Ir}_{0.7} \mathrm{Sn}_{0.3} \mathrm{O}_{2-\mathrm{x}}$ consists of ca. 40 at\% of metallic Ir, which is significantly less stable towards dissolution in comparison to rutile $\mathrm{IrO}_{2}$ [40]. Additionally, the poor catalytic activity of the as-prepared $\mathrm{Ir}_{0.7} \mathrm{Sn}_{0.3} \mathrm{O}_{2-\mathrm{x}}$ means that a higher overpotential is required to achieve the same current density. Considering that electrochemical dissolution increases with potential, the lower stability is to be expected. It should be noted, however, that $\mathrm{SnO}_{2}$ is a relatively poor electronic conductor (semiconductor), which means that some potential drop may take place in the catalyst itself. Hence, the potential at the outer Helmholtz plane can be significantly lower. Interestingly, during the first $30 \mathrm{~min}$ of anodic polarization, about $18 \mathrm{ng} \mathrm{cm}^{-2}$ of $\mathrm{Ir}$ is dissolved from $\mathrm{Ir}_{0.7} \mathrm{Sn}_{0.3} \mathrm{O}_{2-\mathrm{x}}$, which is similar to that observed in the Ir-Ni system with 70 at $\%$ of $\operatorname{Ir}[10,34]$. This can be an indication of similar kinetics of initial Ir dissolution for both materials. However, data on the dissolution rates during long-term polarization of Ir-Ni mixed oxide anodes is not found in the literature.

Dissolution rates of both Ir and Sn decrease with time as seen in Fig. 3c, d. A similar trend is observed in the long-term measurements (Fig. 4). However, decrease in dissolution rates observed in these two setups has different origins. In a flow cell, dissolution decreases because of the change in the electrode surface composition during the galvanostatic treatment. In a bulk cell along with surface composition changes, accumulation of dissolution products occurs until steady-state or equilibrium concentration is achieved.

Using the data on the covalent radii of Ir and Sn and densities of the corresponding oxides together with our dissolution data, one can calculate the number of monolayers dissolved from $\mathrm{Ir}_{0.7} \mathrm{Sn}_{0.3} \mathrm{O}_{2-\mathrm{x}}$ anode during anodic polarization. Thus, during the first $10 \mathrm{~min}$ of electrolysis, the amount of dissolved Sn and Ir corresponds to about 70 and $2 \%$ of a monolayer, respectively. After $60 \mathrm{~min}$, these numbers increase to five monolayers and $10 \%$ of a monolayer, respectively. Anodic treatment of electrode during $1400 \mathrm{~min}$ led to removal of Sn from almost ten monolayers, while the dissolution of Ir was still below a monolayer.

Results presented in the current work can be analyzed together with those published previously for Ir-Ru [14] and IrNi mixed oxides [10,34]. This analysis reveals that if a less stable oxide is mixed with Ir, it still undergoes dissolution under the OER conditions, leading to formation of a porous Ir structure. When $\mathrm{IrO}_{2}$ is mixed with $\mathrm{RuO}_{2}$, which is a more active OER electrocatalyst, the overall electrocatalytic performance of the electrode deteriorates with time and reaches what is expected for pure $\mathrm{IrO}_{2}$. On the other hand, activity of Ir-Ni and Ir-Sn mixed oxides gets better with time, which as discussed earlier can be related to the increase in surface area and surface density of active sites.

Taking into account a relatively high activity, a lower content of $\mathrm{Ir}$, and a comparatively low dissolution, $\mathrm{Ir}_{0.7} \mathrm{Sn}_{0.3} \mathrm{O}_{2-\mathrm{x}}$ can be considered as an alternative anode material for application in the acidic OER. However, electrochemical pretreatment of such electrodes leading to removal of Sn would probably be required to avoid contamination of the membrane and the cathode catalyst with Sn. With an eye towards further decreases in Ir utilization, materials containing less than 70 at $\%$ of Ir should be tested also. One should keep in mind however, that rutile $\mathrm{IrO}_{2}$ with its at least two times lower initial dissolution rate is still a more stable material under conditions of the OER. In case more stable materials are required, stoichiometric Ir-Sn oxide mixtures may be worthwhile to look at, even though this implies sacrificing activity. The question of the OER activity and stability of other non-stoichiometric and stoichiometric Ir-Sn mixed oxides will be addressed in following work.

\section{Conclusion}

The activity and stability relationship of reactively sputtered non-stoichiometric $\mathrm{Ir}_{0.7} \mathrm{Sn}_{0.3} \mathrm{O}_{2-\mathrm{x}}$ electrodes during the OER was examined by the means SFC-ICP-MS and XPS. It was found that anodic polarization of the electrode results in intensive preferential removal of $\mathrm{Sn}$ from the oxide matrix and formation of a porous $\mathrm{Ir}^{\mathrm{III}}$-containing structure. The latter had a beneficial role for electrode performance as the activity increased significantly. As an explanation for this phenomenon, an increase in the surface area and/or the surface density of active sites was suggested. Even though much lower, Ir dissolution was still observable and the measured rates were a factor of two higher than that reported for rutile $\mathrm{IrO}_{2}$. With time, the dissolution rate of both $\mathrm{Sn}$ and $\mathrm{Ir}$ decreased in a similar manner. Additional long-term measurements in an hcell revealed that the dissolution rate dropped after $1400 \mathrm{~min}$ of electrolysis and steady-state was established. The total amount of dissolved Ir in this time interval was still lower than that of a single monolayer. On the other hand, more than ten 
monolayers of Sn were lost from the electrode. Owing to its good electrode performance, the resulting material with an Irenriched surface can be considered as promising OER catalyst.

Acknowledgments Open access funding provided by Max Planck Society. O.K. acknowledges financial support from the Alexander von Humboldt Foundation. The authors acknowledge the MAXNET Energy Research Initiative of the Max-Planck Society for financial support. The authors acknowledge the funding of the BMBF project MANGAN (Grant No. 03SF0507).

Open Access This article is distributed under the terms of the Creative Commons Attribution 4.0 International License (http:// creativecommons.org/licenses/by/4.0/), which permits unrestricted use, distribution, and reproduction in any medium, provided you give appropriate credit to the original author(s) and the source, provide a link to the Creative Commons license, and indicate if changes were made.

\section{References}

1. S. Trasatti, Electrochim. Acta 29, 1503-1512 (1984)

2. R. Amadelli, A. Maldotti, A. Molinari, F.I. Danilov, A.B. Velichenko, J. Electroanal. Chem. 534, 1-12 (2002)

3. A.B. Velichenko, D.V. Girenko, N.V. Nikolenko, R. Amadelli, E.A. Baranova, F.I. Danilov, Russ. J. Electrochem. 36, 1216-1220 (2000)

4. N. Danilovic, K.E. Ayers, C. Capuano, J.N. Renner, L. Wiles, M. Pertoso, ECS Trans. 75, 395-402 (2016)

5. S. Cherevko, S. Geiger, O. Kasian, A. Mingers, K.J.J. Mayrhofer, J. Electroanal. Chem. 773, 69-78 (2016)

6. M. Carmo, D.L. Fritz, J. Mergel, D. Stolten, Int. J. Hydrog. Energy 38, 4901-4934 (2013)

7. M. Schalenbach, G. Tjarks, M. Carmo, W. Lueke, M. Mueller, D. Stolten, J. Electrochem. Soc. 163, F3197-F3208 (2016)

8. S.M. Alia, B. Rasimick, C. Ngo, K.C. Neyerlin, S.S. Kocha, S. Pylypenko, H. Xu, B.S. Pivovar, J. Electrochem. Soc. 163, F3105-F3112 (2016)

9. S. Geiger, O. Kasian, B.R. Shrestha, A.M. Mingers, K.J.J. Mayrhofer, S. Cherevko, J. Electrochem. Soc. 163, F3132-F3138 (2016)

10. T. Reier, Z. Pawolek, S. Cherevko, M. Bruns, T. Jones, D. Teschner, S. Selve, A. Bergmann, H.N. Nong, R. Schlögl, K.J.J. Mayrhofer, P. Strasser, J. Am. Chem. Soc. 137, 13031-13040 (2015)

11. N. Danilovic, R. Subbaraman, K.C. Chang, S.H. Chang, Y. Kang, J. Snyder, A.P. Paulikas, D. Strmcnik, Y.T. Kim, D. Myers, V.R. Stamenkovic, N.M. Markovic, Angew. Chem. Int. Ed. 53, 1401614021 (2014)

12. R. Kötz, S. Stucki, Electrochim. Acta 31, 1311-1316 (1986)

13. V.A. Saveleva, L. Wang, W. Luo, S. Zafeiratos, C. Ulhaq-Bouillet, A.S. Gago, K.A. Friedrich, E.R. Savinova, J. Phys. Chem. Lett, 3240-3245 (2016)

14. O. Kasian, S. Geiger, P. Stock, G. Polymeros, B. Breitbach, A. Savan, A. Ludwig, S. Cherevko, K.J.J. Mayrhofer, J. Electrochem. Soc. 163, F3099-F3104 (2016)

15. O. Diaz-Morales, S. Raaijman, R. Kortlever, P.J. Kooyman, T. Wezendonk, J. Gascon, W.T. Fu, M.T.M. Koper, Nat. Commun. 7, $12363(2016)$
16. L.C. Seitz, C.F. Dickens, K. Nishio, Y. Hikita, J. Montoya, A. Doyle, C. Kirk, A. Vojvodic, H.Y. Hwang, J.K. Norskov, T.F. Jaramillo, Science 353, 1011-1014 (2016)

17. V.V. Gorodetskii, V.A. Neburchilov, Russ. J. Electrochem. 41, 971$978(2005)$

18. S. Ferro, D. Rosestolato, C.A. Martínez-Huitle, A. De Battisti, Electrochim. Acta 146, 257-261 (2014)

19. O.I. Kasian, T.V. Luk'yanenko, P. Demchenko, R.E. Gladyshevskii, R. Amadelli, A.B. Velichenko, Electrochim. Acta 109, 630-637 (2013)

20. O.I. Kasian, T.V. Luk'yanenko, A.B. Velichenko, Protection of Metals and Physical Chemistry of Surfaces 49, 559-566 (2013)

21. I. Chiaki, I. Meguru, T. Hideo, Chem. Lett. 8, 225-228 (1979)

22. D. Chen, C. Chen, Z.M. Baiyee, Z. Shao, F. Ciucci, Chem. Rev. 115, 9869-9921 (2015)

23. T. Kishi, K. Shiota, Surf. Coat. Technol. 34, 287-293 (1988)

24. S.J. Freakley, J. Ruiz-Esquius, D.J. Morgan, Surface and Interface Analysis (2017)

25. V. Pfeifer, T.E. Jones, J.J. Velasco Vélez, C. Massué, R. Arrigo, D. Teschner, F. Girgsdies, M. Scherzer, M.T. Greiner, J. Allan, M. Hashagen, G. Weinberg, S. Piccinin, M. Hävecker, A. KnopGericke, R. Schlögl, Surf. Interface Anal. 48, 261-273 (2016)

26. V. Pfeifer, T.E. Jones, J.J. Velasco Velez, C. Massue, M.T. Greiner, R. Arrigo, D. Teschner, F. Girgsdies, M. Scherzer, J. Allan, M. Hashagen, G. Weinberg, S. Piccinin, M. Havecker, A. KnopGericke, R. Schlogl, Phys. Chem. Chem. Phys. 18, 2292-2296 (2016)

27. A.A. Topalov, I. Katsounaros, J.C. Meier, S.O. Klemm, K.J. Mayrhofer, The Review of scientific instruments 82, 114103 (2011)

28. R. Kötz, H. Neff, S. Stucki, J. Electrochem. Soc. 131, $72-77$ (1984)

29. H.G. Sanchez Casalongue, M.L. Ng, S. Kaya, D. Friebel, H. Ogasawara, A. Nilsson, Angew. Chem. Int. Ed. 53, 7169-7172 (2014)

30. L. Kövér, Z. Kovács, R. Sanjinés, G. Moretti, I. Cserny, G. Margaritondo, J. Pálinkás, H. Adachi, Surf. Interface Anal. 23, 461-466 (1995)

31. Q. Ni, D.W. Kirk, S.J. Thorpe, J. Electrochem. Soc. 162, H40-H46 (2015)

32. J. Augustynski, M. Koudelka, J. Sanchez, B.E. Conway, J. Electroanal. Chem. Interfacial Electrochem. 160, 233-248 (1984)

33. S. Cherevko, S. Geiger, O. Kasian, A. Mingers, K.J.J. Mayrhofer, J. Electroanal. Chem. 774, 102-110 (2016)

34. T. Reier, H.N. Nong, D. Teschner, R. Schlögl, P. Strasser, Adv. Energy Mater. 7, 1601275 (2017)

35. J.Y. Ying, A. Tschöpe, Chapter 10 - Gas-Phase Synthesis of Nonstoichiometric Nanocrystalline Catalysts A2 - Moser, William R, Advanced Catalysts and Nanostructured Materials, Academic Press, San Diego, 1996, pp. 231-257

36. A. Daghetti, G. Lodi, S. Trasatti, Mater. Chem. Phys. 8, 1-90 (1983)

37. M. Pourbaix, Atlas of electrochemical equilibria in aqueous solutions (1974)

38. S. Cherevko, T. Reier, A.R. Zeradjanin, Z. Pawolek, P. Strasser, K.J.J. Mayrhofer, Electrochem. Commun. 48, 81-85 (2014)

39. M.K. Debe, Nature 486, 43-51 (2012)

40. S. Cherevko, S. Geiger, O. Kasian, N. Kulyk, J.-P. Grote, A. Savan, B.R. Shrestha, S. Merzlikin, B. Breitbach, A. Ludwig, K.J.J. Mayrhofer, Catal. Today 262, 170-180 (2016) 